\section{$038-039$ \\ Debate e Investigación}

Introducción

\section{PH50 - Octubre 2004}

\title{
Introducción \\ Del patrimonio de las élites culturales al patrimonio de la sociedad democrática
}

\author{
Javier Rivera Blanco' > Román Fernández-Baca Casares"
}

En el presente año de 2004 se celebran los 50 de la redacción y publicación de la Carta de Venecia, un suceso que marcó definitivamente la evolución de los trabajos de conservación y restauración de bienes inmuebles en los últimos lustros. Desde entonces, las revisiones de este importante documento, aún vigente en algunos de sus aspectos, se ha afrontado con nuevos documentos internacionales, como las Cartas de Toledo y Granada, Amsterdam y Nairobi o la más reciente Carta de Cracovia 2000. La transformación del concepto y de los sujetos del Patrimonio ha sido extraordinaria, pues en la primera fecha fijada eran objetos monumentales los grandes edificios de la arquitectura tradicional religiosa y civil, los centros históricos declarados, los grandes centros de las ruinas clásicas y pocos elementos más.

Durante estas últimas cinco décadas el concepto propio de Patrimonio se ha incrementado de manera impredecible, al trocarse el "Monumento" por un nuevo referente cultural, expresión de objeto de la "identidad de los pueblos" y resultado de la "elección directa de las comunidades y los ciudadanos", según expresó la mencionada Carta de Cracovia. Las fronteras se fueron ampliando constantemente.

Esta transformación se ha producido desde finales del siglo XVIII y durante toda la centuria del siglo XIX hasta el presente. Fue en aquellos tiempos remotos cuando, al amparo del racionalismo y el romanticismo, surgió la conciencia de la historia que llevó a declarar "monumentos nacionales" los edificios más notables de cada civilización en Europa por parte de las élites culturales, desde aquellos memorables textos de Winckelmann, Goethe, Vitet, Merimée, Hugo, Pío VII, etc., que comportaron la selección para salvaguardar para el futuro de los grandes monumentos clásicos y medievales. Nacía así también dirigida por aquellos grupos dirigentes "la identidad colectiva" que asumía el patrimonio como memoria de los pueblos. Pero debemos recordar que en este proceso y hasta hace apenas treinta años los objetos construidos que se declaraban lo eran por su valor histórico y/o artístico, así reconocidos por las élites culturales con una actitud heredada del despotismo ilustrado. La revolución reciente del momento actual ha conocido la democratización de las sociedades y de su voluntad cultural, de manera que los bienes ahora reivindicados lo son por las comunidades y las instituciones sociales y para toda la colectividad. Como ha escrito André de Naeyer, el "Monumento", de "quia monet mentem", ha pasado a ser un Bien Cultural o Patrimonio, con acepciones distintas, sujetos mucho más amplios y puntos de partida más diversos para afrontar su conservación. Se ha convertido en cualquier tipo de pieza o edificio, paisaje o territorio, con cualquier tipo de "memoria".

De esta manera, la Arqueología Industrial, la arquitectura del Movimiento Moderno, la Jardinería, el Paisaje y el Territorio, los objetos de la Ciencia y de la Técnica, la idea de la Materia y de la Forma desde la visión de los pueblos orientales y afro-americanos contra la del eurocentrismo hasta hace poco dominante, lo
Intangible y Espiritual, etc., han penetrado con ímpetu en la conciencia de la historia de los años finales del siglo XX y comienzos del XXI. Hasta tal punto ha ocurrido que en el momento presente la UNESCO ha creado incluso la categoría de Obra Maestra Oral e Inmaterial del Patrimonio de la Humanidad, en el que se catalogan por ejemplo la plaza de Jemaa al Fna de Marrakech, el Misterio de Elche, el Ballet Real de Camboya, el carnaval de Barranquilla o la recitación védica en India. Estos fenómenos nos fuerzan a recordar aquella afirmación de André Malraux, que defendia que el gran descubrimiento del hombre moderno habia sido "la fruición de la belleza", un inédito modelo de belleza, innovación que explicaría que los seres humanos se vieran, como nunca había ocurrido antes, fuertemente atraídos por las obras de arte y del pasado explicando aquellas inmensas colas a las puertas del Hermitage o del Louvre o el fenómeno del turismo cultural, también resultado de la democratización de las sociedades y de sus individuos. Esta misma evolución de la ideología explicaria también la reciente e incontenible atracción por la memoria y por muchas de las realizaciones de los predecesores, hasta ahora en gran parte olvidadas y en grave riesgo de desaparición a pesar de la cultura tecno-científica y global que se ha apoderado de nuestro tiempo y de nuestros modos de vida y que, indudablemente, cada vez más, marcará las vías de desarrollo en el futuro.

En el ámbito puro de la conservación y de la restauración del patrimonio, ello ha comportado también la necesaria evolución en la terminología, en la aplicación de una verdadera pluridisciplinariedad de participantes y en la transformación total de las metodologías y de los criterios. En el pasado el proyecto era obra de un autor, el arquitecto; en la actualidad es el resultado de un amplio equipo en el que trabajan numerosos agentes y expertos en patrimonio, con distintas disciplinas que abarcan desde la Historia, la Arqueología, la Construcción, la Física, la Química, la informática, etc., y siempre con el objetivo de tratar el "Bien" en beneficio de la sociedad, con intensos valores emocionales, personales y colectivos, que no sólo encuentra en él un referente ideológico, sino también una fuente de respuestas contemporáneas de todo tipo, desde las económicas a las espirituales.

Más, junto a la democratización de la cultura y de la conservación en todas sus vertientes y de la cada vez más intensa participación en ellas de la sociedad civil, tampoco podemos olvidar, que las actividades de la restauración son un hecho intelectual que nunca debe dejar de competer y ser dirigida por los profesionales y los expertos cada vez más y mejor cualificados. Es por ello, por lo que los investigadores y los conservadores han movilizado el conjunto de las ciencias del hombre y de la sociedad para desarrollar esta política patrimonial, en definitiva, el resultado de la política cultural que cada pueblo adopta.

Es en este sentido en el que nace y se desarrolla el número 50 de la revista $\mathrm{PH}$ que dedica el presente volumen de manera 
I Javier Rivera Blanco. Catedrático de Historia de la Restauración. Universidad de Valladolid

" Román Fernández-Baca Casares. Director del Instituto Andaluz del Patrimonio Histórico muy especial a procurar una revisión de varios de estos conceptos y a plantear un estado de la cuestión de la conservación y la restauración del patrimonio construido. Aparece, en consecuencia, planteando una llamada a uno de los conceptos más modernos que se están desarrollando en la actualidad, y que define la misma revista, lo que denominamos "la restauración democrática", pues hoy y cada vez más y con la esperanza de que en el inmediato futuro sea de forma determinante, tanto la definición del Bien de Interés Cultural como los intereses hacia su conservación parten de la comunidad, cada vez más concienciada en la salvaguardia de lo que estima representa su herencia cultural. De ahí que el vocablo democracia se integre plenamente en la intervención del Patrimonio. Bastaría apreciar como acciones recientes de actuación en este sentido, como las restauraciones llevadas a cabo en la Catedral de Vitoria, en el David de Miguel Ángel, en las bóvedas de Asís, en los edificios arruinados de Berlín, por citar sólo algunos ejemplos, que concitan cada vez más la participación activa no sólo de las administraciones y los técnicos, sino también de numerosos sectores de la sociedad.

En la sección primera se recogen estudios de vertiente más teórica en los que se plantean algunas de las novedades de los últimos tiempos, como los problemas contemporáneos de la pluridisciplinariedad, o de la autenticidad y la conservación e intervención en cuanto a la materia y la forma, así como los nuevos conceptos del paisaje. La trascendencia de los criterios como resultado de los estudios previos, de la metodología aplicada en el conocimiento del objeto y de la necesidad de dominar las técnicas tradicionales y las nuevas tecnologías -que constantemente se están renovando-, todo ello conducente a la más amplia y perfecta comprensión del hecho construido.
En otros apartados varios autores bucean en las trayectorias más actuales desarrolladas en nuestro territorio y en casos notables de países vecinos o más lejanos con un patrimonio común o muy semejante al nuestro, explicando algún caso español, mexicano, brasileño, cubano, italiano o francés que se consideran trascendentes por diversos motivos en el debate presente.

Se incluyen asimismo referencias amplias sobre instituciones dedicadas a la conservación del patrimonio inmueble, junto con una relación de centros que imparten master y cursos de postgrado sobre la materia. Tampoco se ha querido dejar al margen un nuevo ámbito de difusión y comunicación de las acciones llevadas a cabo en el sector como son las ferias europeas que convocan periódicamente a los profesionales y entidades dedicadas a la salvaguardia del patrimonio, con especial presencia de los técnicos y las empresas.

Finaliza la revista con la reproducción de la última gran Carta de la restauración, la Carta de Cracovia 2000, elaborada por casi tres centenares de expertos internacionales pertenecientes a universidades europeas e instituciones de la UNESCO, Patrimonio Mundial, ICOMOS, ICCROM, etc.

El número se cierra con una recopilación de bibliografía especializada en la que se recogen las más importantes aportaciones aparecidas en los últimos tiempos.

Probablemente se echen de menos algunos trabajos dedicados al hecho urbanístico y de las ciudades y centros históricos y a la política del patrimonio (política cultural, política administrativa, política territorial, descentralización del patrimonio, etc.), sendos ámbitos de fuerte desarrollo contemporáneo, pero que han sido considerados de tal magnitud que podrían ocupar monográficos propios.

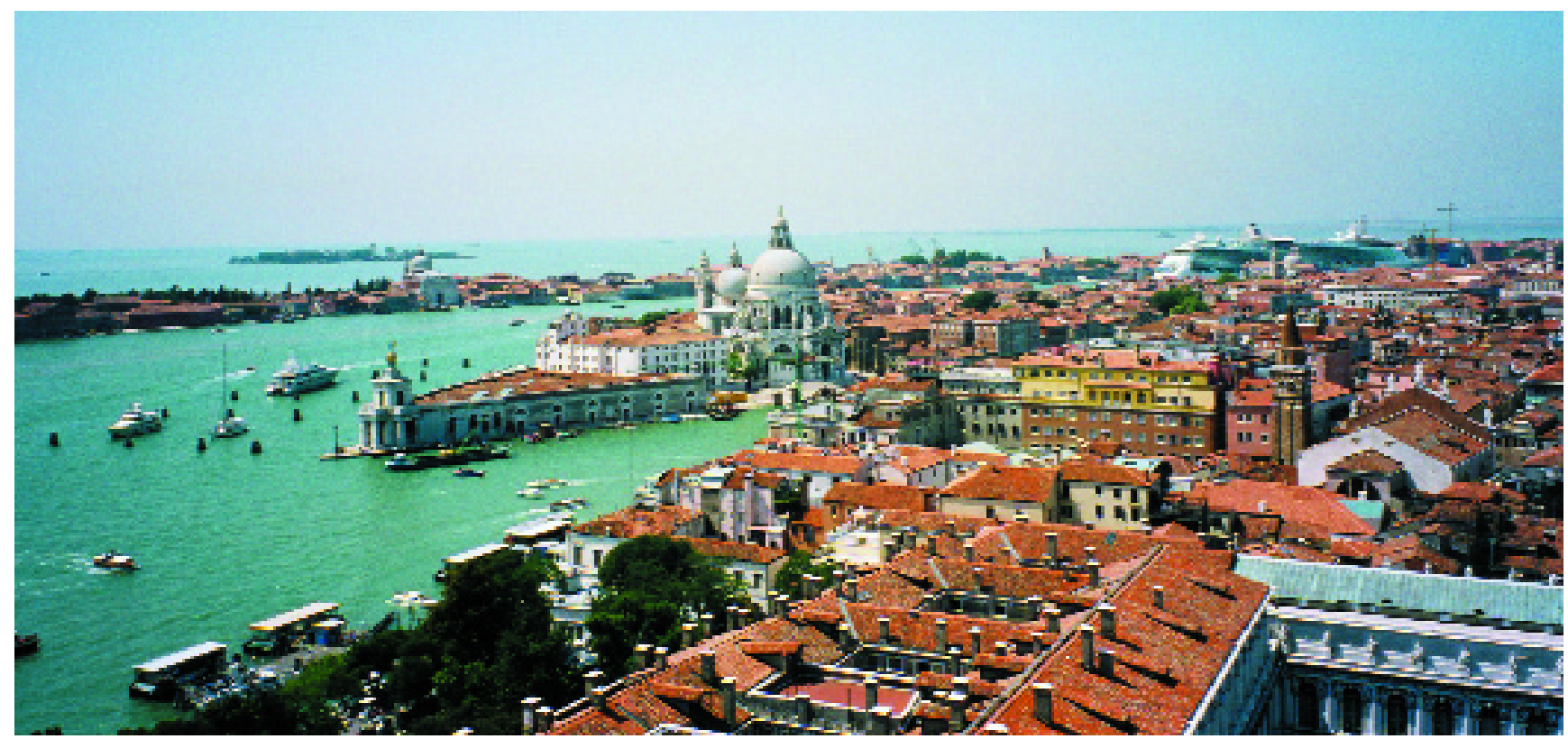

